\title{
Using quality improvement techniques to increase colon cancer screening
}

\author{
Michael P. Pignone, MD, MPH ${ }^{a, b}$ and Carmen L Lewis, MD, MPH ${ }^{a, b}$ \\ ${ }^{a}$ Division of General Internal Medicine and Clinical Epidemiology, University of North Carolina, \\ Chapel Hill, NC, 27599 \\ ${ }^{b}$ Cecil G. Sheps Center for Health Services Research The University of North Carolina at Chapel \\ Hill, 725 Martin Luther King Jr. Blvd. CB\# 7590 Chapel Hill, NC 27599
}

\author{
Keywords \\ colorectal cancer; screening; quality improvement; decision aids
}

\section{Introduction}

\begin{abstract}
In your practice's monthly provider meeting, you and your colleagues review administrative data from a large managed care organization showing that, as a practice, only $45 \%$ of your patients ages 50-75 are up to date with colon cancer screening. Your group decides it wants to improve its performance and asks you to bring a plan back to the next meeting. What are effective means of increasing CRC (colorectal cancer screening in practice)?
\end{abstract}

Colorectal cancer screening has been shown to be effective and cost-effective in reducing the incidence of, and mortality from, colorectal cancer. All major guideline-issuing organizations, including the United States Preventive Services Task Force, recommend colon cancer screening for adults age 50 to $75 .{ }^{1,2}$ Colon cancer screening is one of the highest priorities for preventive care in the US, based on its high potential for reducing morbidity and mortality, and its demonstrated cost-effectiveness. ${ }^{3}$

Despite its demonstrated efficacy and strong potential for positive health impact, colon cancer screening remains underutilized, particularly for under-served populations. Selfreported screening rates are increasing, particularly for those with health insurance. The most recent data from the CDC (Center for Disease Control and Prevention) Behavioral Risk Factor Surveillance System (BRFSS) survey suggest that $60 \%$ of US adults over age 50 are

(C) 2008 Elsevier Inc. All rights reserved.

Corresponding author: Michael P. Pignone MD MPH, Cecil G. Sheps Center for Health Services Research The University of North Carolina at Chapel Hill, 725 Martin Luther King Jr. Blvd. CB\# 7590 Chapel Hill, NC 27599, Michael P Pignone pignone@med.unc.edu, Phone: 919.966.4328, Fax: 919.966.1634.

University of North Carolina-Chapel Hill Department of Medicine, Lineberger Cancer Center, and Cecil Sheps Center for Health Services Research, Chapel Hill, NC

All authors had access to the data and a role in writing this manuscript.

Potential Financial Conflicts of Interests

Michael P. Pignone MD: None

Carmen L Lewis MD MPH: None

Publisher's Disclaimer: This is a PDF file of an unedited manuscript that has been accepted for publication. As a service to our customers we are providing this early version of the manuscript. The manuscript will undergo copyediting, typesetting, and review of the resulting proof before it is published in its final citable form. Please note that during the production process errors may be discovered which could affect the content, and all legal disclaimers that apply to the journal pertain. 
up to date with screening, but levels remain quite low for many groups, including ethnic minorities, the uninsured, and those without a regular source of care. Increased use of screening colonoscopy accounts for much of the recent growth in CRC screening. ${ }^{4}$

Several factors account for the low rates of utilization, including patient, provider and system-related issues. Some barriers, such as lack of health insurance, must be addressed within the larger political and social context. Other barriers, however, can be addressed within the health care system and offer an excellent example of how quality improvement techniques can be used to improve health outcomes.

\section{Interventions to Increasing CRC screening}

A wide variety of interventions have been tested with respect to their ability to increase use of CRC screening. (Table) Our main focus has been the use of patient decision aids. Patient decision aids are tools that have been systematically developed to encourage better decisionmaking processes. They help alert the patient about the relevance of the health issue; allow consideration of options, and their benefits and downsides, and help patients make a decision concordant with his or her values. Our initial trial of a videotape decision aid on CRC screening viewed in clinic found that its use could increase screening by 14 percentage points compared with usual care. ${ }^{5}$ We later updated that decision aid for use on a computer and consideration of newer options for screening, particularly colonoscopy. ${ }^{6}$

The main elements of our decision aid include basic information about colon cancer; that colon cancer incidence and mortality can be prevented by screening, and that several tests are available. Patients are given the option to review one or more of the different tests in detail with respect their efficacy, frequency, degree of preparation required, and cost. Finally, patients are encouraged to express their interest and any questions to their provider. In each of our studies, we made no specific efforts to train providers on the use of the decision aid or to improve office systems. As such, the proportion of patients with tests ordered and completed was lower than the proportion expressing interest in testing after the decision aid.

After establishing the efficacy of a decision aid in the practice, we then focused on measuring the effectiveness and efficiency of mailing the CRC decision aid (in DVD form) and a reminder letter to unscreened patients in our internal medicine practice. We also implemented a systems intervention: standing orders for CRC screening tests so that patients could obtain the tests easily. The intervention increased screening by 11 percentage points, but appeared to work more through reminding the patients than through use of the decision aid. The cost of the intervention was estimated to be $\$ 94$ per additional patient screened. ${ }^{7}$ We have recently tested lower cost mailings (sending only the letter with an option to get the decision aid) and found them to be effective for patients of our attending physicians at a reasonable cost ( $\$ 19$ per additional patient screened); this intervention was not effective, however, for patients of our resident physicians.

Although we have chosen to focus on patient decision aids, current evidence is not sufficient to clearly recommend one approach or combination of approaches as being clearly superior. Several techniques have been shown to modestly increase the use of CRC screening, but existing studies have several limitations. Most have only evaluated occult blood testing, which is a very different service than colonoscopy, and requires different systems for implementation. Most have been conducted in motivated volunteer practices with relatively low baseline screening levels. The evaluated interventions have targeted different barriers to care, and may be synergistic in combination, although few studies have compared rigorously different groups of interventions. 
Ideally, a practice with an average baseline screening level (40-50\%) that wished to improve CRC screening would begin with a relatively high-reach, low-cost strategy with moderate or better usage and efficacy, such as a mailed patient reminder. Full implementation of a reminder would reach all unscreened patients and give them the opportunity for screening. It could be expected to increase screening by 10-20 percentage points. After implementing this first strategy, one or more complementary strategies with higher efficacy and cost could be added to assist the remaining 30-50\% of patients. At some point, the cost per additional patient screened of interventions directed to "late adopters" may become too high to justify further interventions. Currently, we do not have good benchmarks to determine an acceptable cost per additional patient screened, and further economic analyses are required to guide that decision.

\section{Acknowledgments}

Dr. Pignone and Dr. Lewis are supported by research grants from the Foundation for Informed Medical Decision Making. Dr. Lewis is supported by a K07 Mentored Career Development Award and Dr. Pignone by a K05 Established Investigator Award (5K07CA104128 and 1K05CA129166, respectively) from the National Cancer Institute.

The authors would like to thank Jennifer Griffith and Rachael Scheinman for their help in preparing this manuscript.

Funding source: no funders

\section{References}

1. Pignone M, Rich M, Teutsch SM, Berg AO, Lohr KN. Screening for colorectal cancer in adults at average risk: a summary of the evidence for the U.S. Preventive Services Task Force. Ann Intern Med. 2002; 137(2):132-41. [PubMed: 12118972]

2. Pignone M, Saha S, Hoerger T, Mandelblatt J. Cost-effectiveness analyses of colorectal cancer screening: a systematic review for the U.S. Preventive Services Task Force. Ann Intern Med. 2002; 137(2):96-104. [PubMed: 12118964]

3. Maciosek MV, Coffield AB, Edwards NM, Flottemesch TJ, Goodman MJ, Solberg LI. Priorities among effective clinical preventive services: results of a systematic review and analysis. Am J Prev Med. 2006; 31(1):52-61. [PubMed: 16777543]

4. MMWR. Use of colorectal cancer tests--United States, 2002, 2004, and 2006. MMWR Morb Mortal Wkly Rep. 2008; 57(10):253-8. [PubMed: 18340331]

5. Pignone M, Harris R, Kinsinger L. Videotape-based decision aid for colon cancer screening. A randomized, controlled trial. Ann Intern Med. 2000; 133(10):761-9. [PubMed: 11085838]

6. Kim J, Whitney A, Hayter S, et al. Development and initial testing of a computer-based patient decision aid to promote colorectal cancer screening for primary care practice. BMC Med Inform Decis Mak. 2005; 5:36. [PubMed: 16313676]

7. Lewis CL, Brenner AT, Griffith JM, Pignone MP. The uptake and effect of a mailed multi-modal colon cancer screening intervention: A pilot controlled trial. Implement Sci. 2008; 3:32. [PubMed: 18518990] 
Table

Techniques for Increasing Colorectal Cancer Screening in Practice

\begin{tabular}{|l|l|l|l|l|}
\hline Technique & Reach & Use & Effectiveness & Cost-effectiveness \\
\hline Provider Training & Moderate & Variable & Moderate & Moderate \\
\hline Audit and feedback & High & High & Low-moderate & Good \\
\hline Provider reminder systems & High & Variable & Moderate & Start-up costs high; ongoing costs low \\
\hline Provider bonuses & High & High & Low & Unclear \\
\hline Patient reminders & Variable & Variable & Moderate & Variable \\
\hline Patient decision aids & Low-moderate & Low-moderate & Moderate & Unclear \\
\hline Patient financial incentives & High & High & Moderate & Unclear \\
\hline Quality improvement efforts & Low & Variable & Low-moderate & Poor \\
\hline
\end{tabular}

